\title{
A pivotal restructuring of modelling the control of COVID-19 during and after massive vaccination for the next few years
}

Jose B Cruz Jr ( $\square$ joe.cruz@icloud.com )

National Academy of Science and Technology, Philippines https://orcid.org/0000-0002-7420-2823

Tirso A Ronquillo

Batangas State University

Ralph G B Sangalang

Batangas State University

Albertson D Amante

Batangas State University

Divina G D Ronquillo

Batangas State University

Janice F Peralta

Batangas State University

Antonette V Chua

Batangas State University

Oliver L J A Jose

Batangas State University

Raynell A Inojosa

Batangas State University

\section{Research Article}

Keywords: COVID-19, SARS-CoV-2, pandemic, social spread of disease, feedback control of corona virus, closed loop models, interventions for spread of corona virus, Batangas State University engineered closed loop model

Posted Date: April 30th, 2021

DOI: https://doi.org/10.21203/rs.3.rs-145259/v6

License: (c) (i) This work is licensed under a Creative Commons Attribution 4.0 International License.

Read Full License 


\title{
A pivotal restructuring of modelling the control of COVID-19 during and after massive vaccination for the next few years
}

\author{
Jose B. Cruz, Jr. ${ }^{1}$, Tirso A. Ronquillo*2, Ralph Gerard B. Sangalang ${ }^{2}$, Albertson D. Amante ${ }^{2}$, \\ Divina Gracia D. Ronquillo ${ }^{2}$, Janice F. Peralta ${ }^{2}$, Antonette V. Chua ${ }^{2}$, \\ Oliver Lexter July A. Jose ${ }^{2}$, Raynell A. Inojosa ${ }^{2}$ \\ ${ }^{1}$ National Academy of Science and Technology, Taguig City, Philippines \\ ${ }^{2}$ Batangas State University, Rizal Avenue, Batangas City, Philippines
}

\begin{abstract}
This paper presents a new mathematical feedback model to demonstrate how direct observations of the epidemiological compartments of population could be mapped to inputs, such that the social spread of the disease is asymptotically subdued. Details of the stabilization and robustness are included. This is a pivotal restructuring of modelling the control of corona virus from the current models in use world-wide which do not utilize feedback of functions of epidemiological compartments of population to construct the inputs. Although several vaccines have received Emergency Use Authorization (EUA) massive vaccination would take several years to reach herd immunity in most countries. Furthermore, the period of efficacy of the vaccination may be approximately one year only resulting in an unending vaccination. Even during the vaccination, there would be an urgent need to control the spread of the virus. When herd immunity is reached without feedback control and vaccination is discontinued, there could be new surges of the disease. These surges of disease could be prevented in appropriately designed stable feedback models. Moreover, extensive testing, contact tracing, and medical treatment of those found infected, must be maintained.
\end{abstract}

KEYWORDS: COVID-19, SARS-CoV-2, pandemic, social spread of disease, feedback control of corona virus, closed loop models, interventions for spread of corona virus, Batangas State University engineered closed loop model 


\subsection{Introduction and background}

Starting with a very small outbreak of a coronavirus disease in Wuhan, China in December 2019, the World Health Organization (World Health Organization 2020a), on February 11, 2020, labeled the virus as Severe Acute Respiratory Syndrome Coronavirus 2 (SARS-CoV2), and the corresponding disease as Corona Virus Disease 2019 (COVID-19). By the same day, COVID-19 has grown to 43,103 confirmed cases world-wide, 42,708 in China, 395 in 24 other countries, 1,017 deaths in China, and one death for the rest of the world (World Health Organization 2020b). On March 11, 2020, WHO declared COVID-19 as a pandemic. By March 5, 2021, the pandemic has reached 115,289,961 confirmed cases and 2,564,560 deaths world-wide; 28,468,736 confirmed cases and 515,013 deaths in the United States; and 535,207 confirmed cases and 12,423 deaths in the Philippines (World Health Organization 2020c).. There are other sources of data (Dong et al. 2020, C3ai DTI 2020a, C3ai DTI 2020b). As of December 1, 2020, there have been new surges of COVID-19 infection, for a variety of reasons, in many parts of the world, and the pandemic is still raging (Dong et al. 2020).

Several interventions have been employed to mitigate the exponential growth of COVID-19 such as quarantine or lockdown, wearing of masks, physical distancing, and frequent washing of hands. However, these interventions are unevenly practiced in some countries, and in many others, they are lifted soon after they "flatten the curve", leading to unstable behavior again.

Recently, several pharmaceutical companies have received Emergency Use Authorization (EUA) for use of vaccines in the last two (2) weeks of 2020, and more companies and more vaccines are now available in 2021. Initial availability would be limited to health care providers and other high-risk segments of the population. How should the vaccines be 
allocated? (Emmanuel et al. 2020). Allocations can be optimized (Sy et al. 2020). Each political jurisdiction will decide on prioritization and optimization. For the rest of the global population, some pharmaceutical companies have announced that more vaccines will be available by the middle of 2021 . These companies are still investigating the duration of efficacy of the vaccines. For the near term, there is a need to continue the interventions, or innovative ways to modify the interventions so they will become more effective. It is expected that massive vaccination will be available later this year and in the next two (2) years.

Is there further need for modelling the trend of COVID-19? Yes.

(a) If 100,000 persons can be vaccinated everyday, it will take two (2) years to vaccinate $80 \%$ of the Philippine population, assuming vaccinations that require only one shot.

(b) The duration of efficacy of the various vaccines is not known at this time. If the efficacy duration is one (1) year, massive vaccination is needed for the foreseeable future with no end in sight.

(c) During the vaccination period of several years, can the current models used worldwide be used to mitigate the growth of disease spread? After more than a year of COVID-19 pandemic, the Philippines and the entire world are still suffering from the raging disease. A new type of intervention is needed, a pivotal restructuring of modelling the control of corona virus.

\subsection{Review of science models of disease spread}

The first mathematical model to describe the spread of a disease was published in 1927 (Kermack and McKendrick 1927). The basic idea in the model is to divide the population into epidemiological compartments. In the Kermack and McKendrick model, the compartments of 
population $N$ are: Susceptible $(S)$, Infected $(I)$, and Removed $(R)$. The rates of change with respect to time of $S, I$, and $R$, are modeled as functions of $S, I$, and $R$, respectively. This model has been adopted for modeling the spread of COVID-19, with several layers of subsocieties, and each layer with more compartments beyond $S, I$, and $R$, such as Exposed $(E)$, Hospitalized $(H)$, and further subdivision of $I$ into Symptomatic and Asymptomatic (Chen et al. 2020). Others have further analyzed the Wuhan outbreak (Kucharski et al. 2020, Ndairou et al. 2020, Saad-Roy et al. 2020, Britton et al. 2020). SARS-CoV-2 is known to mutate, and mutation of viruses during propagation has been studied (Eletreby et al. 2019). There are updates available for the progression of COVID-19 (World Health Organization 2020c) including a science model with the updates (Dong et al. 2020). The effect of virus mutation, on therapeutics for COVID-19, has been studied also (Hou et al. 2020), and it appears that the mutation D614G propagates faster than the original SARS-CoV-2. They state that "current vaccine approaches directed against the WT (wild-type) spike should be effective against the D614G strains." (Hou et al. 2020).

In the only paradigm in use today, interventions are deployed to change the environment, resulting in changing direction of observations, and subsequent revised mathematical models. When the interventions are relaxed or removed altogether, subsequent observations will show that the disease spread will increase exponentially and the process repeats.

The main purpose of this paper is to provide a new engineered closed loop model for stabilizing systems such as a model for the social spread of disease. As in existing science models, the engineered closed loop model in this paper addresses the macro-scale level of modeling the spread of a disease, not necessarily COVID-19. The simplest science model is considered to modify into an engineered closed loop feedback system to focus on the advantages of closed loop models. 


\subsection{Review of SIR science model}

The starting point in the development of an engineered closed loop model with feedback of observation in Section 3 is the Kermack and McKendrick model (1927). Figure 1 shows a diagram of the Science Model. There are three differential equations but only two are independent because of the constraint $S+I+R=N$, where $S=$ Susceptible, $I=$ Infected, $R=$ Removed and $N=$ Population

Normalizing the compartments of $N, s=\frac{s}{N}, i=\frac{I}{N}, r=\frac{R}{N}$, the constraint becomes $s+i+r=1$. The rate of change with respect to time of $s$ and the rate of change of $r$ with respect to time are the postulated models

$$
\begin{gathered}
\frac{d s}{d t}=-\beta s i \\
\frac{d r}{d t}=\gamma i
\end{gathered}
$$

where $\beta$ is the infectivity rate and $\gamma$ is the recovery rate.

The rate of change of $i$ with respect to time follows from the constraint,

$$
\begin{gathered}
\frac{d s}{d t}+\frac{d i}{d t}+\frac{d r}{d t}=0 \\
\frac{d i}{d t}=\beta s i-\gamma i
\end{gathered}
$$

\subsection{Review of the SIFD science model}

In the SIR model, the compartment $R$ is divided into two sub-compartments, $F$ and $D$, where $F$ is the number of persons that are Free of Virus but possessing antibodies, and $D$ is the 
number of persons that are Deceased. As in the SIR model, $S, I, F$, and $D$, respectively, are normalized by dividing each by $N$, yielding

$$
s+i+f+d=1
$$

Figure 1 still represents the science model. The rate equations for $s, f$, and $d$, respectively, are the proposed behavioral postulates as in (Kermack and McKendrick 1927)

$$
\begin{gathered}
\frac{d s}{d t}=-\beta s i \\
\frac{d f}{d t}=\gamma(1-\delta) i \\
\frac{d d}{d t}=\gamma \delta i .
\end{gathered}
$$

The rate equation for $i$ is obtained from the constraint:

$$
\frac{d s}{d t}+\frac{d i}{d t}+\frac{d f}{d t}+\frac{d d}{d t}=0 .
$$

yielding Equation (4).

Observations are used to calibrate the parameters $\beta, \gamma$, and $\delta$. Analysis of the mathematical models leads to obtaining conditions that cause exponential growth, suggesting how instability can be avoided. A typical intervention in science models is to change the environment, such as modification in the use of (a) quarantine or lock down, (b) face masks, (c) physical distancing, and (d) contact tracing. These modifications in interventions can change the calibrated values of $\beta, \gamma$, and $\delta$ so that stability can be achieved, after several cycles of modifications in the environment. It should be noted that the modifications in environment are carried out first and then the science model is constructed. However, experimental assessment of the effectiveness of the model is carried out after it is 
constructed. Thus by increasing interventions the resulting system could become stable, but removing the intervention would eventually make the system unstable.

\subsection{Pivoting from science model to Batangas State University engineered feedback model}

There are two steps in the transition. The first step is to create explicit inputs to the science model. The second step is to construct a mapping from the outputs to the inputs of the science model.

\subsection{Creating the Batangas State University input-output model}

The first step in pivoting from a science model to an engineered feedback model is to explicitly create inputs to the science model as indicated in Figure 2. In the science model, the environment could be regarded as input but it is not treated as an external signal. There are intrinsic benefits to creating models with inputs and outputs (Tan et al. 2018). In this paper we create two inputs to the SIFD science model.

As in the science model without inputs, the rate equations, for $s, f$, and $d$, are postulated. The rate equation for $i$ is derived from the constraint in Equation (9) where the quantities $z_{1}$ and $z_{2}$ are inputs.

$$
\begin{gathered}
\frac{d s}{d t}=-\beta s i+z_{1} \\
\frac{d i}{d t}=\beta s i-\gamma i-z_{1}-z_{2} \\
\frac{d f}{d t}=\gamma(1-\delta) i+z_{2}
\end{gathered}
$$

and Equation (8). Equation (10) is a modification of the Equation (6) and it is one of the equations for the input - output model. Equation (12) is a modification of Equation (7) and it is a second equation for the input - output model. Equation (8) of the SIFD model is retained 
as a third equation for the input - output model. The fourth equation for the model, Equation (11), is obtained from Equation (9),

$$
\frac{d i}{d t}=-\frac{d s}{d t}-\frac{d f}{d t}-\frac{d f}{d t}
$$

and Equations (8), (10) and (12). Thus, Equations (8), (10) and (12) are modelling statements similar to the science model, Equations (6), (7) and (8), except that in the Batangas State University model, inputs $\mathrm{z}_{1}$ and $\mathrm{z}_{2}$ have been added.

The input $z_{1}$, when scaled up to $z_{1} * \mathrm{~N}$, is the number of persons per day that we plan to change the decrease in the susceptible rate $S$ per day by. It has a simultaneous partial effect of opposite change in the infected $I$ per day.

The input $z_{2}$ when scaled up to $z_{2} * \mathrm{~N}$ is the additional increase in the number of persons per day that are free of virus and have antibodies in them, $F$ per day. It has a simultaneous partial effect of reducing the infected $I$ per day.

The Batangas State University input-output model is dynamic and nonlinear.

\subsection{Creating the Batangas State University pivotal engineered feedback model}

Figure 3 shows the diagram of the closed loop system. One of the key advantages of adding feedback to an input - output system is the capability to stabilize the entire system ( $\mathrm{Aström}$ and Murray 2020, Albertos and Mareels 2010, Cruz 1971, Dorf and Bishop 2004 and Kuo and Golnaraghi 2002). The design of the two inputs of the Batangas State University inputoutput model in two-stages. The input $z_{1}$ is divided into two parts:

$$
z_{1}=z_{1 N}+z_{1 L}
$$

where $z_{1 N}=B_{a} s i$ 
The value of $\beta$ in the science model is usually uncertain or variable but $B_{a}$ is chosen to match a specific value, $\beta^{*}$. The value of $B_{a}$ may be chosen adaptively based on a sequence of estimates of $\beta$ (Kanellakopoulos et al. 1991) but for simplicity, the value of $\beta^{*}$ is chosen only once. In the simulations, it is assumed that there are four different values of $\beta: 0.20,0.23$, 0.25 and 0.28. Choosing $B_{a}=\beta^{*}=0.20$ and $z_{1 N}=B_{a} s i$, the engineered model for $\beta=\beta^{*}$ becomes linear as indicated in Equations (8), (14), (15), (16)

$$
\begin{gathered}
\frac{d s}{d t}=z_{1 L} \\
\frac{d i}{d t}=-\gamma i-z_{1 L}-z_{2} \\
\frac{d f}{d t}=\gamma(1-\delta) i+z_{2} .
\end{gathered}
$$

The quantities $s, i, f$, and $d$ are represented by $s=s_{d}+\Delta s, i=i_{d}+\Delta i, f=f_{d}+\Delta f$, and $d=d_{d}+\Delta d$. The quantities $s_{d}, i_{d}, f_{d}$, and $d_{d}$ are desired constant asymptotes where $i_{d}$ is always set equal to 0 .

The first three linear differential equations can be written in matrix form as

$$
\begin{aligned}
& {\left[\begin{array}{c}
\frac{d \Delta s}{d t} \\
\frac{d \Delta i}{d t} \\
\frac{d \Delta f}{d t}
\end{array}\right]=\left[\begin{array}{ccc}
0 & 0 & 0 \\
0 & -\gamma & 0 \\
0 & \gamma(1-\delta) & 0
\end{array}\right]\left[\begin{array}{c}
\Delta s \\
\Delta i \\
\Delta f
\end{array}\right]+\left[\begin{array}{cc}
1 & 0 \\
-1 & -1 \\
0 & 1
\end{array}\right]\left[\begin{array}{c}
Z_{1 L} \\
z_{2}
\end{array}\right]} \\
& A=\left[\begin{array}{ccc}
0 & 0 & 0 \\
0 & -\gamma & 0 \\
0 & \gamma(1-\delta) & 0
\end{array}\right]
\end{aligned}
$$


$B=\left[\begin{array}{cc}1 & 0 \\ -1 & -1 \\ 0 & 1\end{array}\right]$

It can be readily verified that any value of the state is reachable and $(A, B)$ is controllable (Åström and Murray 2020). Denoting the vector input by

$\left[\begin{array}{c}z_{1 L} \\ z_{2}\end{array}\right]=-K\left[\begin{array}{l}\Delta s \\ \Delta i \\ \Delta f\end{array}\right]$

where

$K=\left[\begin{array}{lll}k_{1} & k_{2} & k_{3} \\ k_{4} & k_{5} & k_{6}\end{array}\right]$

The three eigenvalues of $A-B K$ can be specified arbitrarily. In particular, the eigenvalues can be set to be real and negative.

For illustrative purposes, the three eigenvalues are chosen as $\lambda \approx-0, \lambda=-0.05, \lambda=-0.05$, the parameter $B_{a}=0.20$ and the six coefficients in the matrix $\mathrm{K}$ as stated earlier. For simulation, the values for $\beta$ are: $0.20,0.23,0.25$ and 0.28 .

The matrix, $\mathrm{K}$, is calculated in MATLAB Control Toolbox using the command

$\mathrm{K}=\operatorname{place}(\mathrm{A}, \mathrm{B}, \mathrm{p})$.

Based on Equations 13, 20, 21, $z_{1 N}=B_{a}$ si and $B_{a}=\beta^{*}$ the final structure of the Batangas State University engineered nonlinear closed loop model equations are

$$
\begin{aligned}
& \frac{d \Delta s}{d t}=-\left(\beta-B_{a}\right)\left(s_{d} \Delta i+\Delta s \Delta i\right)-k_{1} \Delta s-k_{2} \Delta i-k_{3} \Delta f \\
& \frac{d \Delta i}{d t}=\left(\beta-B_{a}\right)\left(s_{d} \Delta i+\Delta s \Delta i\right)-\gamma \Delta i+k_{1} \Delta s+k_{2} \Delta i+ \\
& k_{3} \Delta f+k_{4} \Delta s+k_{5} \Delta i+k_{6} \Delta f
\end{aligned}
$$




$$
\begin{gathered}
\frac{d \Delta s}{d t}=-\left(\beta-B_{a}\right)\left(s_{d} \Delta i+\Delta s \Delta i\right)-k_{1} \Delta s-k_{2} \Delta i-k_{3} \Delta f \\
\frac{d \Delta f}{d t}=\gamma(1-\delta) \Delta i-k_{4} \Delta s-k_{5} \Delta i-k_{6} \Delta f \\
\frac{d \Delta d}{d t}=\gamma \delta \Delta i .
\end{gathered}
$$

It is assumed that $\beta$ remains in a certain range that includes $\beta^{*}$. Summarizing, the Batangas State University feedback control is

$$
\left[\begin{array}{l}
z_{1} \\
z_{2}
\end{array}\right]=\left[\begin{array}{c}
B_{a} s i \\
0
\end{array}\right]-K\left[\begin{array}{c}
\Delta s \\
\Delta i \\
\Delta f
\end{array}\right]
$$

where $B_{a}=\beta^{*}$ and $K$ is the matrix defined in Eq 21 under the condition that $\beta=\beta^{*}$. $\beta^{*}$ is a design parameter chosen as one of the possible values of $\beta$ such as the minimum value of $\beta$. Earlier, $\beta^{*}$ was set to 0.20 .

\subsubsection{Setting the target asymptotic values, system parameters and initial conditions}

Using the Philippine population: 109,581,078 and data from the Philippine Department of Health, $I_{0}=32,031, D_{0}=10,136, F_{0}=467,720$, as of January 22, 2021 (COVID 19 Update2021) and the constraint: $s_{0}+i_{0}+f_{0}+d_{0}=1$. Initial values: $s_{0}=0.995347$, $\mathrm{i}_{0}=2.923 \times 10^{-4}, \mathrm{f}_{0}=0.004268, \mathrm{~d}_{0}=9.249772 \times 10^{-5}$. The initial values for $\Delta s, \Delta i, \Delta f$, and $\Delta d$ are $s_{0}-s_{d}, i_{0}, f_{0}-f_{d}, d_{0}-d_{d}$, respectively.

Note that the constraint is given by $s_{d}+f_{d}+d_{d}=1$. If vaccines are available, set $f_{d}$ to be quite high, for example $f_{d}=0.6$. Set $d_{d}>d_{0}, d_{d}=1.095 \times 10^{-4}$. Thus, $s_{d}=0.4-1.095 \mathrm{x}$ $10^{-4}=0.39989$. Based on available data, the other system parameters were estimated to have values of $\gamma=0.20$ and $\delta=0.02$.

\subsection{Simulations}

Figures 4, 5, 6, and 7 display results when feedback is present. 
In Figures 4 and 6, the plots for $S$ and $F$, respectively, it is not possible to visually distinguish the curves for four different values of $\beta$, displaying not only stability, but also robustness as well. In Figure 5, the plot of the infected compartment of Philippine population, $I$, shows the four projections for different values of $\beta$. Note that the scale of $I$ and $\mathrm{D}$, in Figures 5 and 7 is in ten thousands. Thus, $D$ and $I$ hardly affect $S$ and $F$ because $S+I+F+D=N$, where $S, F$, and $N$ are in ten million.

Figures 8 and 9 show the feedback $\mathrm{z}_{1} * \mathrm{~N}$ and $\mathrm{z}_{2} * \mathrm{~N}$ with initial values of 3.2 million people per day. The simulation is for illustrative purpose only and in an actual application the eigenvalues for pole placement may have to be increased resulting in a slower decay to match the capacity for massive vaccination. Figures 10 and 11 provides details of the components of $\mathrm{z}_{1} * \mathrm{~N}$.

Figures 12 and 13, show plots of $I$ and $D$ respectively, when feedback is not present, $z_{1}=0$ and $z_{2}=0$. Notice that in Figure 12, when $\beta=0.28$, the maximum value of $I$ is 4.8 million out of 108 million population. For the other values of $\beta$, the values of $I$ in Figure 12 are also unacceptably large, except for $\beta=2.0$. Figure 13 shows the graphs of mortality for different values of $\beta$ which are also unacceptably large, except for $\beta=2.0$. In contrast, when feedback control is applied ( $\mathrm{z}_{1}$ and $\mathrm{z}_{2}$ are present), Figures 4 to 11 indicate dramatically better results.

\subsection{Relationship of controls to interventions}

Vaccination intervention is related to control $\mathrm{z}_{2}$. The number of vaccinations need to be counted and related to the desired increase provided by $\mathrm{z}_{2}$. If $\mathrm{z}_{2}$ is greater than the maximum capacity for vaccinations the maximum capacity would be used otherwise the eigenvalues need to be adjusted. The control $z_{1}$ is related to the intervention of wearing mask, social distancing and quarantine. If the control $z_{1}$ is greater than the maximum requirements of 
wearing mask, social distancing and quarantine, the maximum could be utilized or the eigenvalues could be adjusted. In an actual application, iterative adjustments may be needed.

\subsection{Stabilization and robustness properties of Batangas State University engineered closed}

\section{loop model}

The principal advantage of utilizing a closed loop model that includes a feedback mechanism for mapping the output to the input of the systems is the possibility of stabilization (Cruz 1971, Åström and Murray 2020, Åström and Kumar 2014), and increasing the stability margin. The Batangas State University engineered closed loop model is designed to be stable. There is extensive literature on stabilization available (Albertos and Mareels 2010, Dorf and Bishop 2004 and Kuo and Golnaraghi 2002), for example. Simulations show that the model remains stable for a range of values of $\beta$. Furthermore, the simulations show that the outputs are robust against variations in the value of $\beta$ (Cruz and Perkins 1964, Cruz et al. 1981a, Cruz et al. 1981b, Freudenberg et al. 1982).

\subsection{Comparison of interventions in science models and engineered closed loop models}

\subsection{Science models}

The prevailing method for the study of disease propagation, such as the spread of COVID-19 is through the construction of mathematical models. Typically, these models consist of sets of differential equations with parameters that are chosen so that computer simulations using the models would show results that closely approximate of real observations. If the observations indicate that the disease keeps growing, the model can be helpful in identifying what environmental conditions influence the growth. For example, the mathematical model could determine that some transmissivity parameters might have values that are too high, and interventions such as increased isolation of infected persons or increased use of face masks 
are warranted. With the interventions, as suggested by the model, new observations might indicate that growth has stopped or even reversed, and revised models would show that the new situations are stable. If the interventions are removed, there might be resurgence of growth in the spread of the disease. If the fixed intervention is not removed, it would be maintained at the latest level until a resurgence occurs for whatever reason. Note that the latest model is obtained after the latest change in the environment. However, experimental assessment of the effectiveness of the latest model is conducted after it is constructed.

\subsection{Engineered closed loop models}

The principal reason for using an engineered closed loop mathematical model, that adds a feedback mechanism of measured epidemiological compartments of population, to construct the inputs of the input-output model, is to provide a capability to stabilize the composite model (Åström and Murray 2020, Cruz 1971). Parameters of the input-output model are determined as in Section 4.1, using observations without feedback. However, experimental assessment of the effectiveness of the closed loop model cannot be accomplished until the processes of the closed loop model are in place. This is the same situation as in the science model because the effectiveness of the most recent science model can only be assessed after new observations are made and compared with the predicted outputs of the science model. Thus, policy makers need to allow that the interventions be modulated in accordance with the process of the closed loop model. As in the science model, new observations can be gathered to verify if the computer calculations of the closed loop model are reasonable approximations of new real observations. One major capability of using a closed loop model is that even if the input-output model is unstable, potentially, the entire system with feedback can be stable. When the closed loop model is designed to be stable, then the epidemiological compartments of population would tend to the designed asymptotic values, but the closed loop structure 
needs to be in place indefinitely. Testing will remain and if there is occasional infection, the infected persons will receive medical treatment, as appropriate, and contact tracing will be conducted. A second advantage of using a closed loop model is that it can be robust against variations in the parameters, such as the infectivity rate, $\beta$ (Cruz and Perkins 1964, Cruz et al. 1981a, Cruz et al. 1981b, Freudenberg et al. 1982).

\subsection{Other closed loop models}

The only closed loop model in the literature was proposed by a team from the University of Montreal (Stewart et al. 2020). They used an input-output model proposed by the University of Notre Dame (Kantor 2020).

\subsubsection{Notre Dame University input-output model}

The University of Notre Dame model (Kantor 2020) added an input to the Kermack and McKendrick SIR Science Model (Kermack and McKendrick 1927). A control input $u$ is introduced by multiplying $\beta$ by $(1-u)$ in the science model

$$
\begin{aligned}
& \frac{d s}{d t}=-(1-u) \beta s i \\
& \frac{d i}{d t}=(1-u) \beta s i-\gamma i
\end{aligned}
$$

together with Equation (2).

In Kantor (2020), simulations were performed for various fixed values of $u$, where $0<u<1$, to demonstrate mitigation of the propagation of COVID-19. 


\subsubsection{University of Montreal closed loop model}

A University of Montreal team (Stewart et al. 2020) took the University of Notre Dame model and used the control input $u$ to propose a closed loop function of the number of hospital beds available in a city. Several scenarios were discussed, including use of alternating fixed and output-dependent interventions. Their goal was to use feedback control to stabilize the system. However, the paper does not provide details of how the number of available hospital beds is related to the state variables of the model. No details are provided in the paper as to what the mathematical expression of the control $u$ is, and no details are provided as to how their chosen $u$ stabilizes the system.

\subsubsection{Comparing the Notre Dame/Montreal model with the Batangas State University engineered closed loop model}

The Notre Dame model introduced a multiplier $(1-u)$ wherever $\beta$ appears. It has the conceptual effect of reducing the value of $\beta$, very similar to the science model of changing the environment to alter the value of $\beta$. In the Montreal closed loop model, their team proposed to use $u$ of the Notre Dame model as a feedback function of the available hospital beds. The ultimate impact of this feedback function on stability would be quite complicated, without having a detailed analysis, not available in the literature. The Batangas State engineered closed loop model introduces the intervention at a broader level, without committing to reducing the value of $\beta$. The inputs $z_{1}$ and $z_{2}$ directly influence the rate of change of $s, i$, and $f$. Furthermore, the input $z_{2}$ implies utilizing vaccination, without increasing the infected compartment. This paper is the first to incorporate the effect of vaccination on input-output modeling of the spread of a disease. Furthermore, this paper is first to consider the use of a vaccine in a closed loop model incorporating a feedback 
mechanism to relate observations of epidemiological compartments of population, to the two modulated inputs or interventions.

\subsection{Concluding remarks}

The major contribution of this paper was the design of the Batangas State University engineered feedback model that utilizes the outputs in tempering the inputs to control the spread of COVID-19. The model was designed to be stable and robust against variations in the values of transmissivity, $\beta$. The Batangas State University engineered closed loop model introduced an input $\left(z_{2}\right)$ utilizing feedback, that led to a substantial increase in the number of epidemiological compartment of population that is Free of virus $(F)$, without significant increase in the number of Infected (I). Even when the spread is reduced to almost zero, testing, contact tracing, and medical treatment of those tested positive, must continue as part of the closed loop process, to avoid new surges of infection, and further reduce mortality. The specific design using specific eigenvalues is for illustrative purpose. Before applying to an actual situation, various capacities need to be determined and the eigenvalues need to be chosen so that the values of the controls do not exceed the capacities.

\subsection{Acknowledgments}

Jose B Cruz Jr. acknowledges support from the National Academy of Science and Technology for a Research Fellowship. The authors would also like to acknowledge Batangas State University for all the support and opportunity to complete this project.

\subsection{References}

Albertos, P. and Mareels, I. Feedback and Control for Everyone. Springer, 2010.

Åström KJ and Murray RM. Feedback systems, Second Edition, Princeton University Press. 2020. http://www.cds.caltech.edu/ murray/amwiki/index.php/Second_Edition 
Åström KJ and Kumar PR. Control: a perspective. Automatica 2014; 50:3-43.

Britton T, Ball F, Trapman P. A mathematical model reveals the influence of population heterogeneity on herd immunity to SARS-CoV-2. Science Vol 369(6505):846-849. DOI 10.1126/science.abc6810. 2020.

Chen T-M, Rui J, Wang Q-P, Zhao Z-Y, Cui J-A, and Yin L. A mathematical model for simulating the phase-based transmissibility of a novel coronavirus. 2020. Infectious Diseases of Poverty. https://doi.org/10.1186/s40249-020-00640-3

Covid-19 Updates, Philippines 2020. Updated daily. http://www.doh.gov.ph/

C3ai DTI. Digital Transformation Institute. c3dti.ai. 2020a.

C3ai DTI. Digital Transformation Institute. Data on COVID-19. 2020b. https://c3.ai/products/c3-ai-covid-19-data-lake/

Cruz JB. Feedback in systems. Chapter I, in Cruz JB, ed., Feedback systems, McGraw-Hill NY 1971, 1-18.

Cruz JB and Perkins WR. A new approach to the sensitivity problems in multivariable feedback system design. IEEE Trans. on Automatic Control, AC-9(July 1964):216223.

Cruz JB, Freudenberg JS, and Looze DP. A relationship between sensitivity and stability of multivariable feedback systems. IEEE Trans. on Automatic Control, AC-26 (February 1981): Vol AC-26: 66-74.

Cruz JB, Looze DP, and Perkins WR. Sensitivity analysis of nonlinear feedback systems. J. Franklin Institute 1981b; 312(3/4):199-215.

Dong E, Du H, Gardner L. An interactive web-based dashboard to track COVID-19 in real time. The LANCET Infectious Diseases. 20(5):533-534. February 19, 2020. Johns Hopkins University. https://doi.org/10.1016/S1473-3099(20)30120-1. Also see https://systems.jhu.edu/

Dorf, R. C. and Bishop, R. H. Modern Control Systems. Prentice Hall, Upper Saddle River, NJ, 10th edition, 2004.

Eletreby R, Zhuang Y, Carley KM, Yagan O, Poor HV. The effect of evolutionary adaptations on spreading processes in complex networks. Proc. National Academy of Sciences, USA March 17, 2020; 117(11):5664-5670. 
Emmanuel EJ, Persad G, Upshur R, Thome B, Parker M, Glickman A, Zhang C, Boyle C, Smith M, Phillips JP. Fair allocation of scarce medical resources in the time of COVID-19. The New England Journal of Medicine 2020; 382:2049-2055. https://nejm.org/doi/full/10.1056/nejmsb2005114.

Franklin, G. F. Powell, J. D. and Emami-Naeini, A. Feedback Control of Dynamic Systems. Prentice Hall, Upper Saddle River, NJ, 5th edition, 2005.

Freudenberg JS, Looze DP, and Cruz JB. Robustness analysis using singular value sensitivities. International J. of Control 1982; 35(1):95-116.

Hou YJ, Chiba S, Halfmann P, Here C, Kuroda M, Dinnon KHIII, Leist SR, Schafer A, Nakajima N, Takashi K, Lee RE, Mascenik TM, Graham R, Edwards CE, Tse LV, Okuda K, Markmann AJ, Bartelt L, de Silva A, Margolis DM, Boucher RC, Randell SH, Suzuki T, Gralinski LE, Kawaoka Y, Baric RS. SARS-CoV-2 D614G variant exhibits efficient replication ex vivo and transmission in vivo. Science 12 Nov 2020: eabe8499. DOI: 10.1126/science.abe8499.

Kanellakopoulos, I, Kokotovic, PV, Morse, AS. Systematic design of adaptive controllers for feedback linearizable systems, IEEE Transactions on Automatic Control, 36 (11) 1241-1253, 1991.

Kantor JC. COVID-19 simulation model. 2020. https://apmonitor.com/do/index.php/Main/COVID-19Response

Kermack WO, and McKendrick AG. A contribution to the mathematical theory of epidemics. Proceedings of the Royal Society of London 1927; 115:700-721. http://acdc2007.free.fr/kermack1927.pdf

Kucharski AJ, Russell TW, Diamond C, Liu Y, Edmunds J, Funk S, Eggo RM. Early dynamics of transmissivity and control of COVID-19: a mathematical modeling study. The LANCET Infectious Diseases May 1, 2020; 20(5): 553-558. https://doi.org/10.1016/S1473-3099(20)30144-4

Kuo, B. C. and Golnaraghi, F. Automatic Control Systems. Wiley, New York, 8th edition, 2002.

Ndairou F, Area I, Nieto JJ, Torres DFM. Mathematical modeling of COVID-19 transmission dynamics with a case study of Wuhan. Chaos, Solitons and Fractals June 2020; Vol. 135. https://doi.org/10.1016/j.chaos.2020.109846

Saad-Roy CM, Wagner CE, Baker RE, Morris SE, Farrar J, Graham AL, Levi SA, Mina MJ, Metcalf CJE, and Grenfell BT. Immune life history, vaccination, and dynamics of SARS-CoV-2 over the next 5 years. Science 370(6518): 811-818. (13 November 2020) 
DOI: $10.1126 /$ science.abd7343.

Stewart G, Heusden KV and Dumont. GA. How control theory can help us control COVID19. IEEE Spectrum 2020; 57(6): 22-29.

Sy CL, Aviso KB, Cayamanda CD, Chiu ASF, Lucas RIG, Promentilla MAB, Razon LF, Tan RR, Tapia JFD, Torneo AR, Ubando AT, and Yu DEC. Process integration for emerging challenges: optimal allocation of antivirals under resource constraints. Clean Technology and Environmental Policy. 2020 Jun 13:1-12. DOI: 10.1007/s10098-020-01876-1.

Tan RR, Aviso KB, Promentilla MAB, Yu KDS, Santos JR. Input-output models for sustainable industrial systems: implementation using LINGO. Springer Singapore 2018.

World Health Organization. 2020a. Naming the coronavirus disease (COVID-19) and the virus that causes it. https://who.int/emergencies/diseases/novel-coronavirus2019/technical-guidance/naming-the-coronavirus-disease-(COVID-19)-and-the-virusthat-causes-it

World Health Organization. 2020b. Novel Coronavirus (2019-nCoV) situation report 22. World Health Organization. https://www.who.int/docs/defaultsource/coronaviruse/situation-reports/20200211-sitrep-22-ncov.pdf

World Health Organization. 2020c. WHO coronavirus disease (COVID-19) dashboard. https://covid19.who.int

\section{Science Model of Corona Virus}

Figure 1. Science model showing outputs or observations

\section{Science Model of Corona Virus}

Figure 2. Creating an input-output model by adding inputs to the science model 


\section{Science Model of Corona Virus}

\section{Controller}

Figure 3. Mapping the outputs or observations to the inputs via a controller

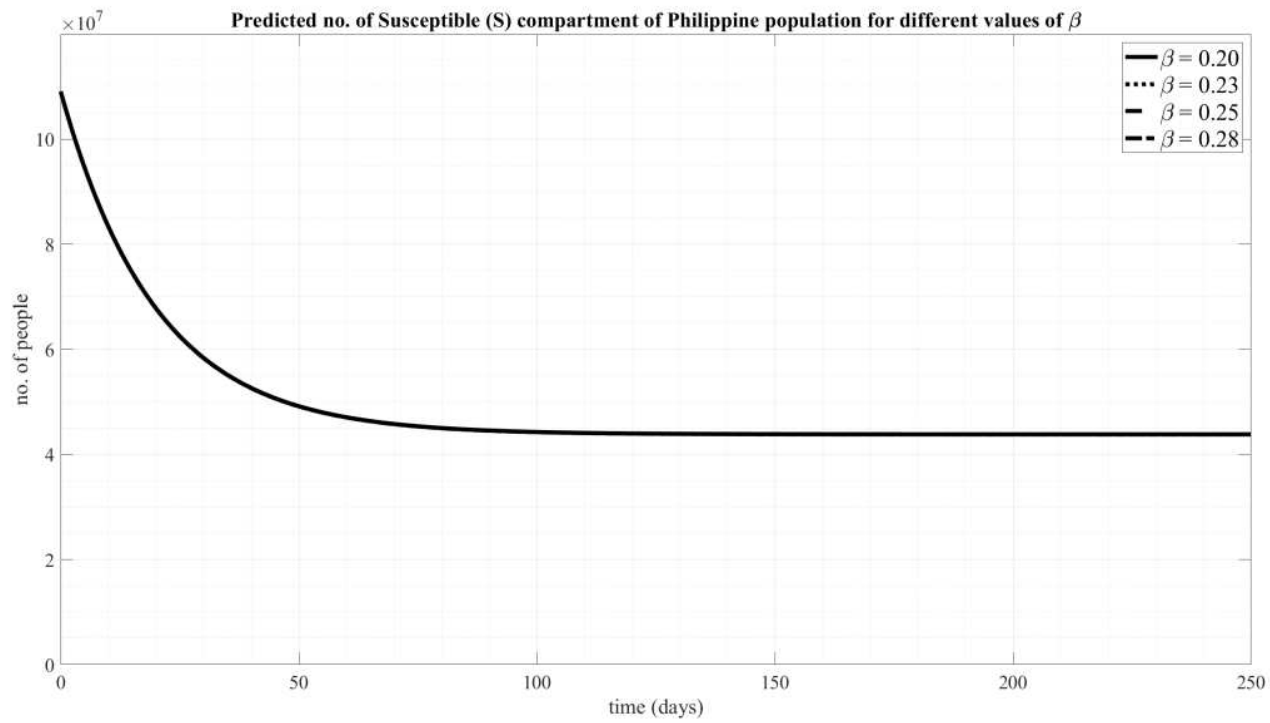

Figure 4. Predicted number of Susceptible (S) compartment of Philippine population for different values of $\beta$ 


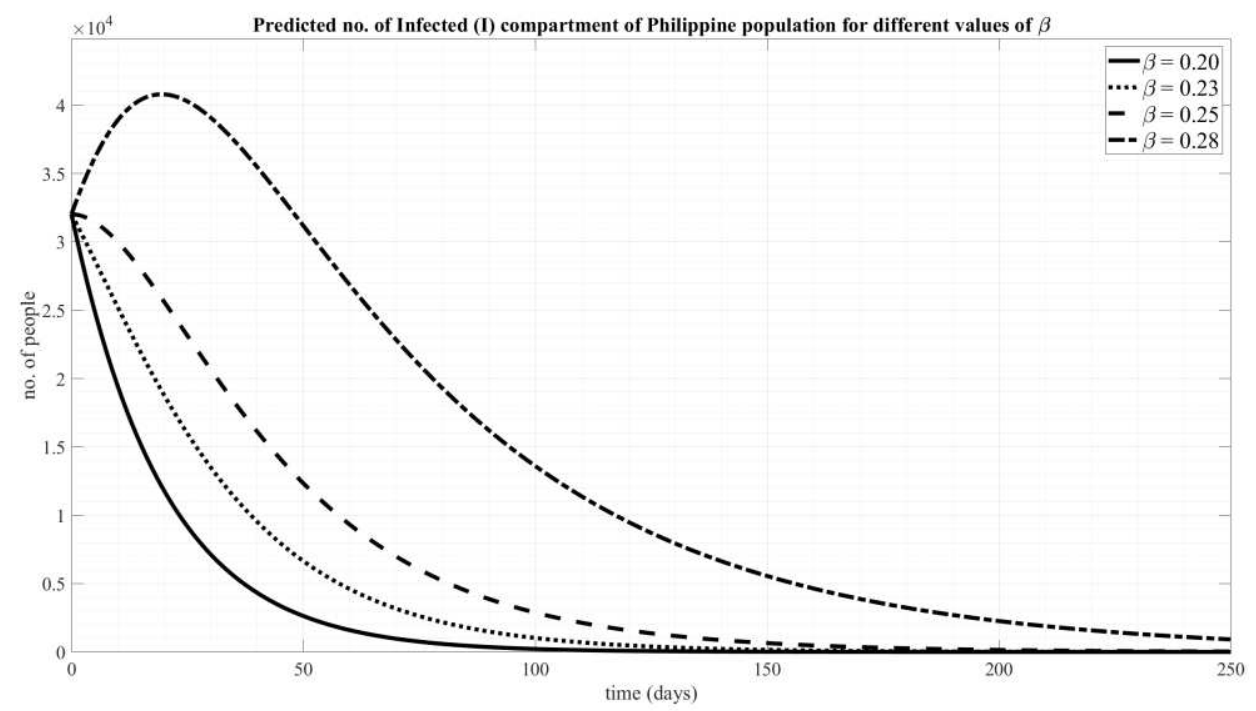

Figure 5. Predicted number of Infected (I) compartment of Philippine population for different values of $\beta$

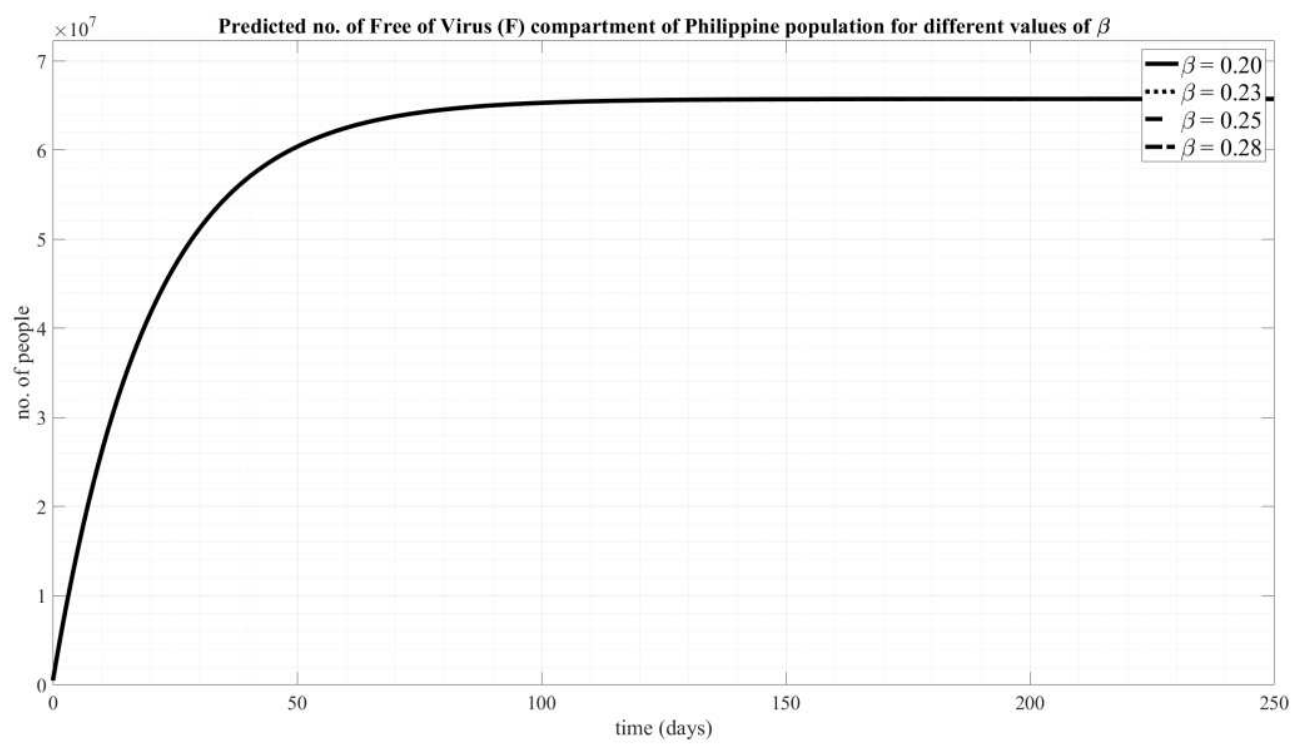

Figure 6. Predicted number of Free of Virus (F) compartment of Philippine population for different values of $\beta$ 


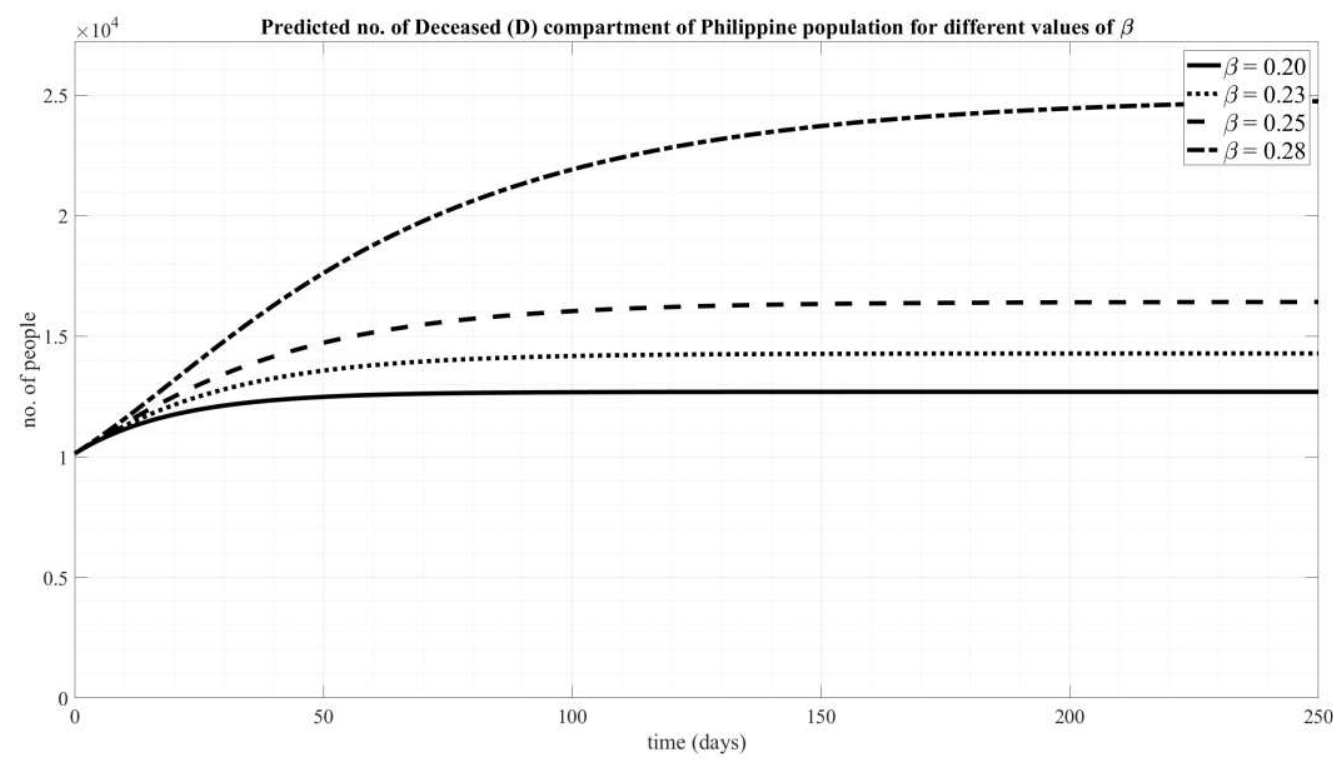

Figure 7. Predicted number of Deceased (D) compartment of Philippine population for different values of $\beta$

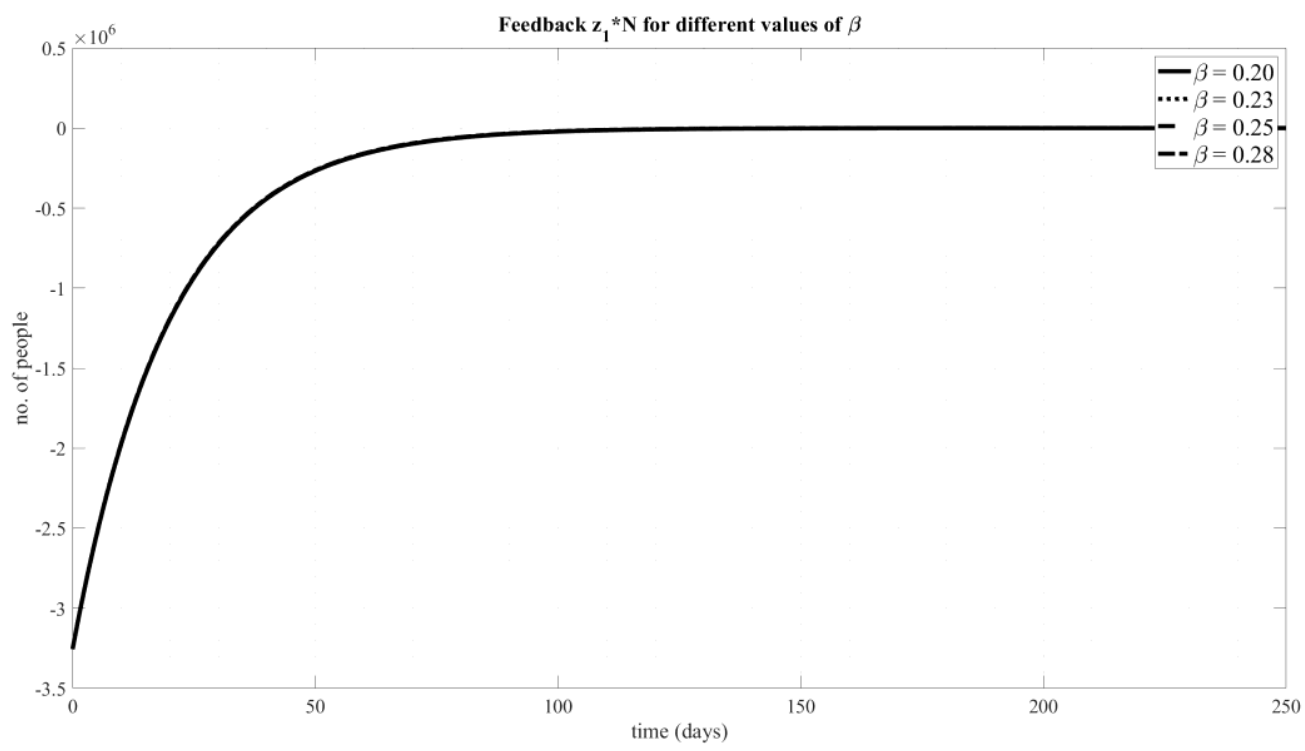

Figure 8 Feedback $\mathrm{z}_{1} * \mathrm{~N}$ for different values of $\beta$ 


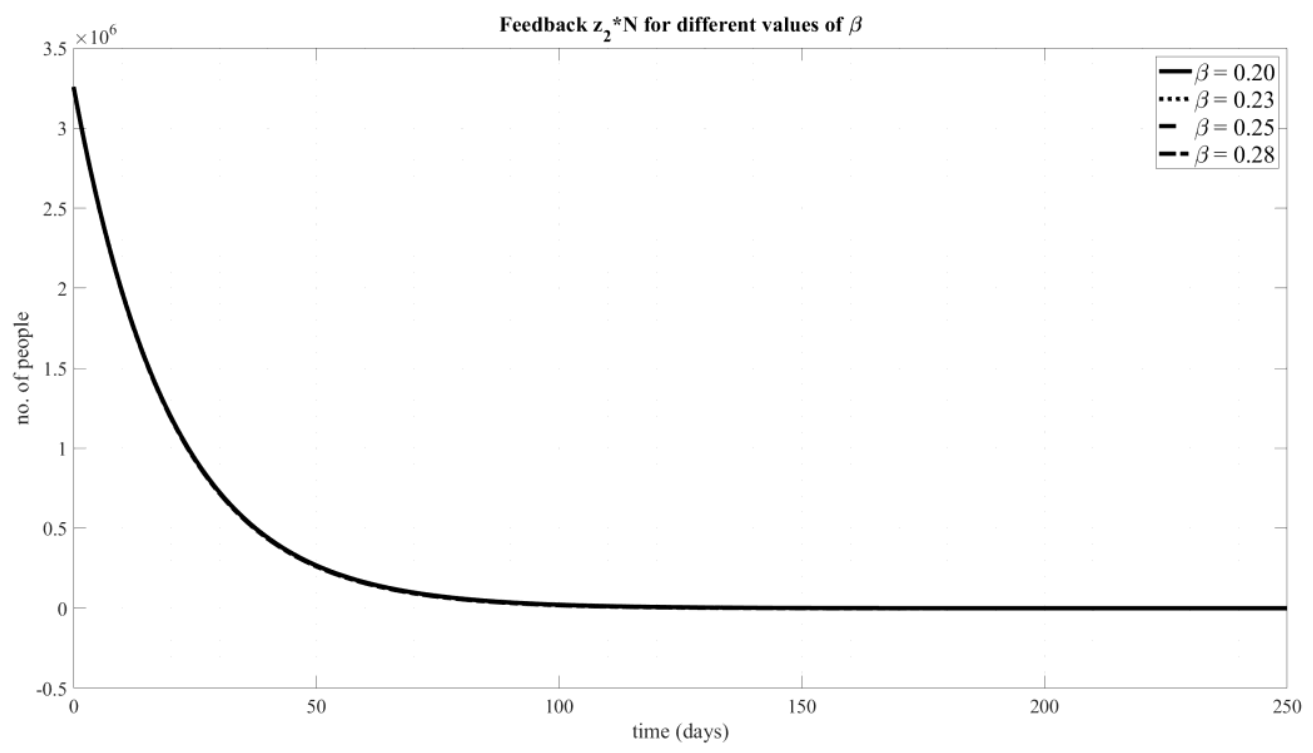

Figure 9 Feedback $\mathrm{z}_{2} * \mathrm{~N}$ for different values of $\beta$

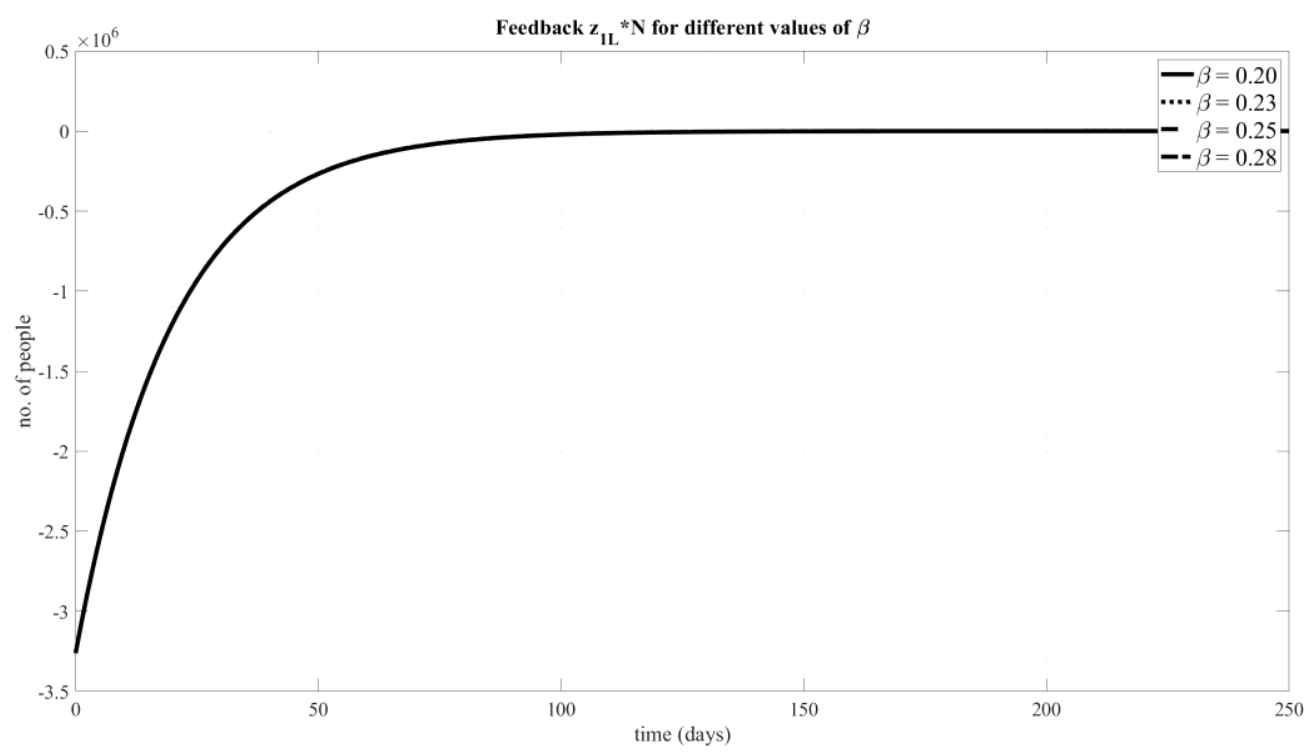

Figure 10 Feedback $\mathrm{z}_{1 \mathrm{~L}} * \mathrm{~N}$ for different values of $\beta$ 


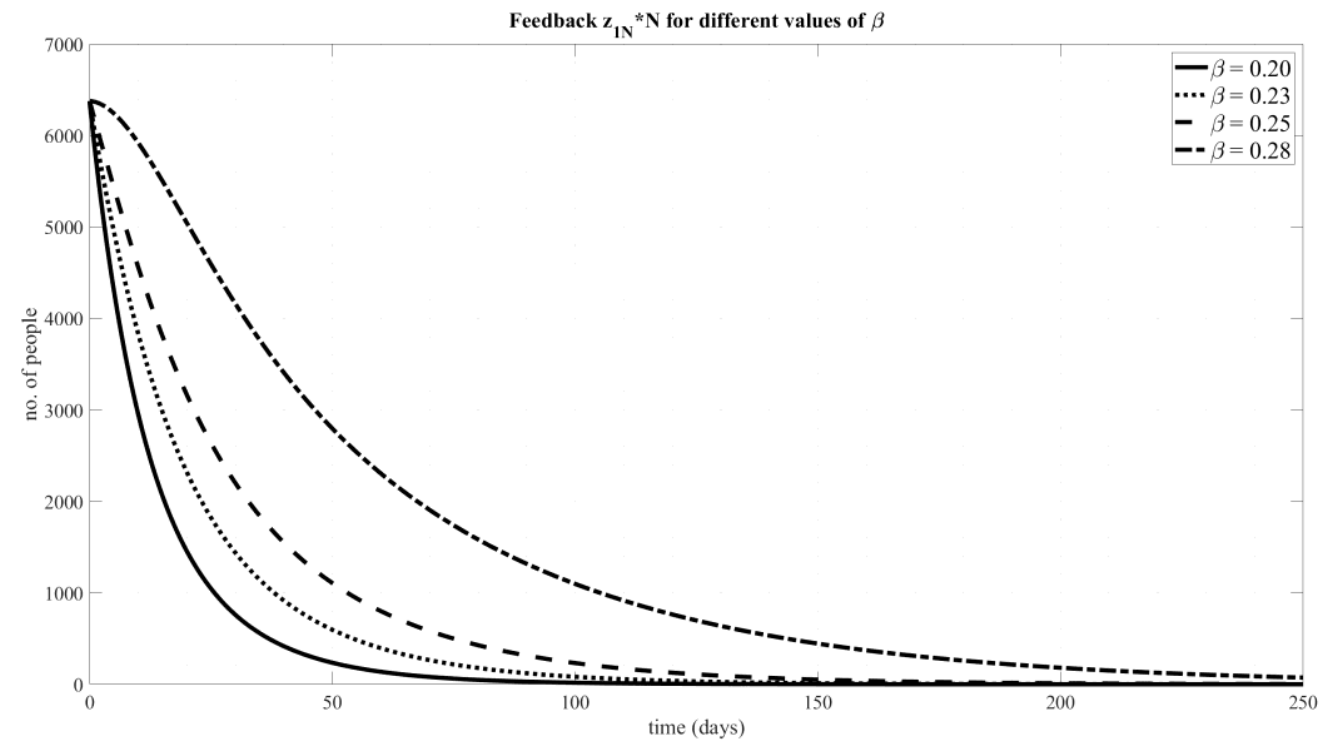

Figure 11 Feedback $\mathrm{Z}_{1 \mathrm{~N}} * \mathrm{~N}$ for different values of $\beta$

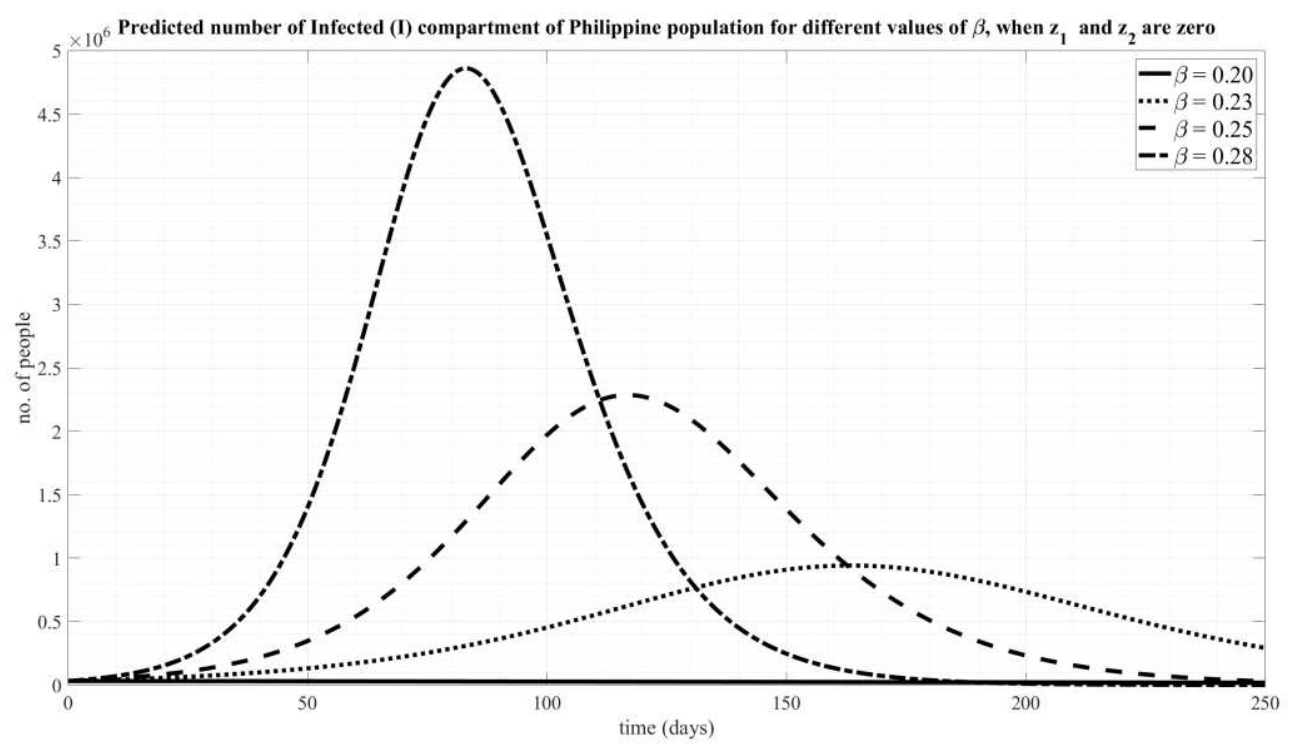

Figure 12. Predicted number of Infected (I) compartment of Philippine population for different values of $\beta$ when $\mathrm{z}_{1}$ and $\mathrm{z}_{2}$ are zero 


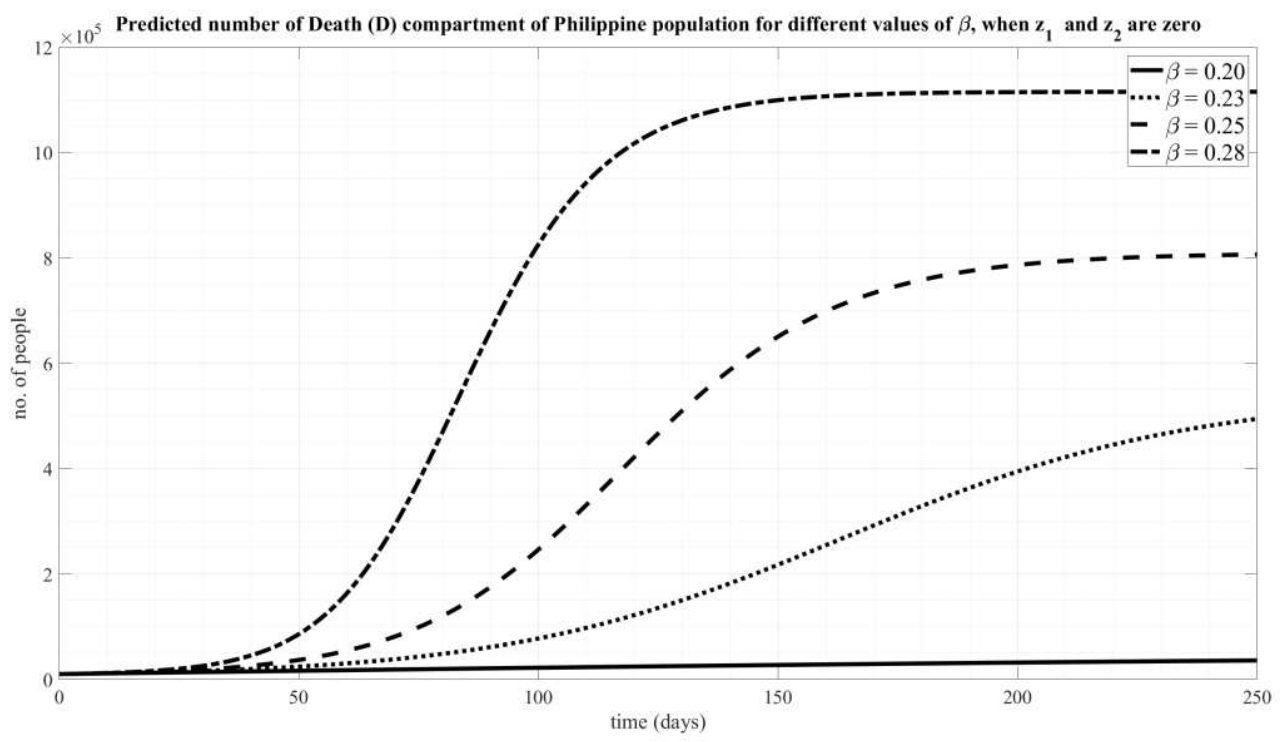

Figure 13. Predicted number of Death (D) compartment of Philippine population for different values of $\beta$ when $\mathrm{z}_{1}$ and $\mathrm{z}_{2}$ are zero 
Figures

\section{Science Model of Corona Virus}

Figure 1

Science model showing outputs or observations

\section{Science Model of Corona Virus}

Figure 2

Creating an input-output model by adding inputs to the science model

\section{Science Model of Corona Virus}

\section{Controller}

Figure 3

Mapping the outputs or observations to the inputs via a controller 


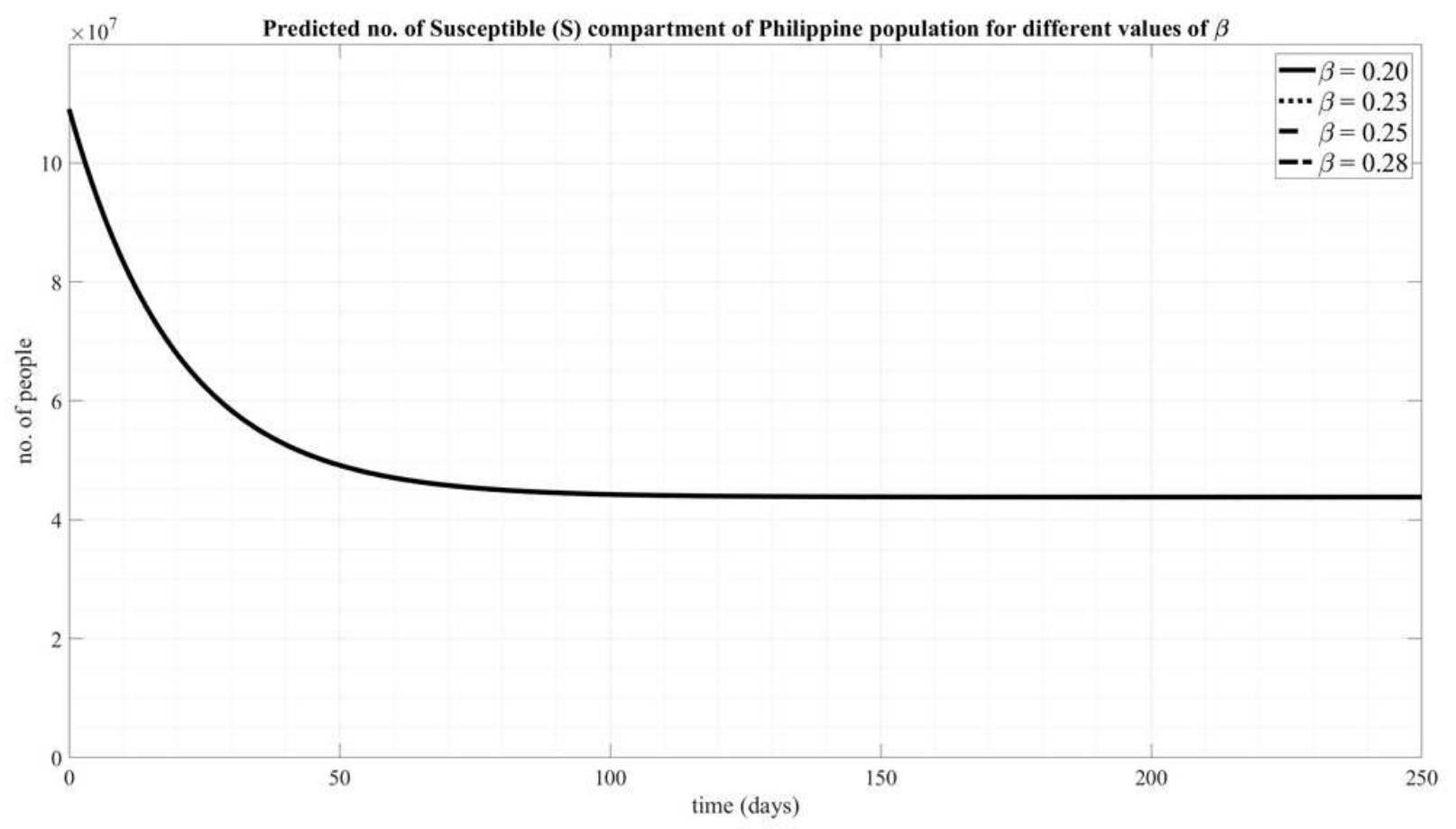

Figure 4

Predicted number of Susceptible (S) compartment of Philippine population for different values of $\beta$

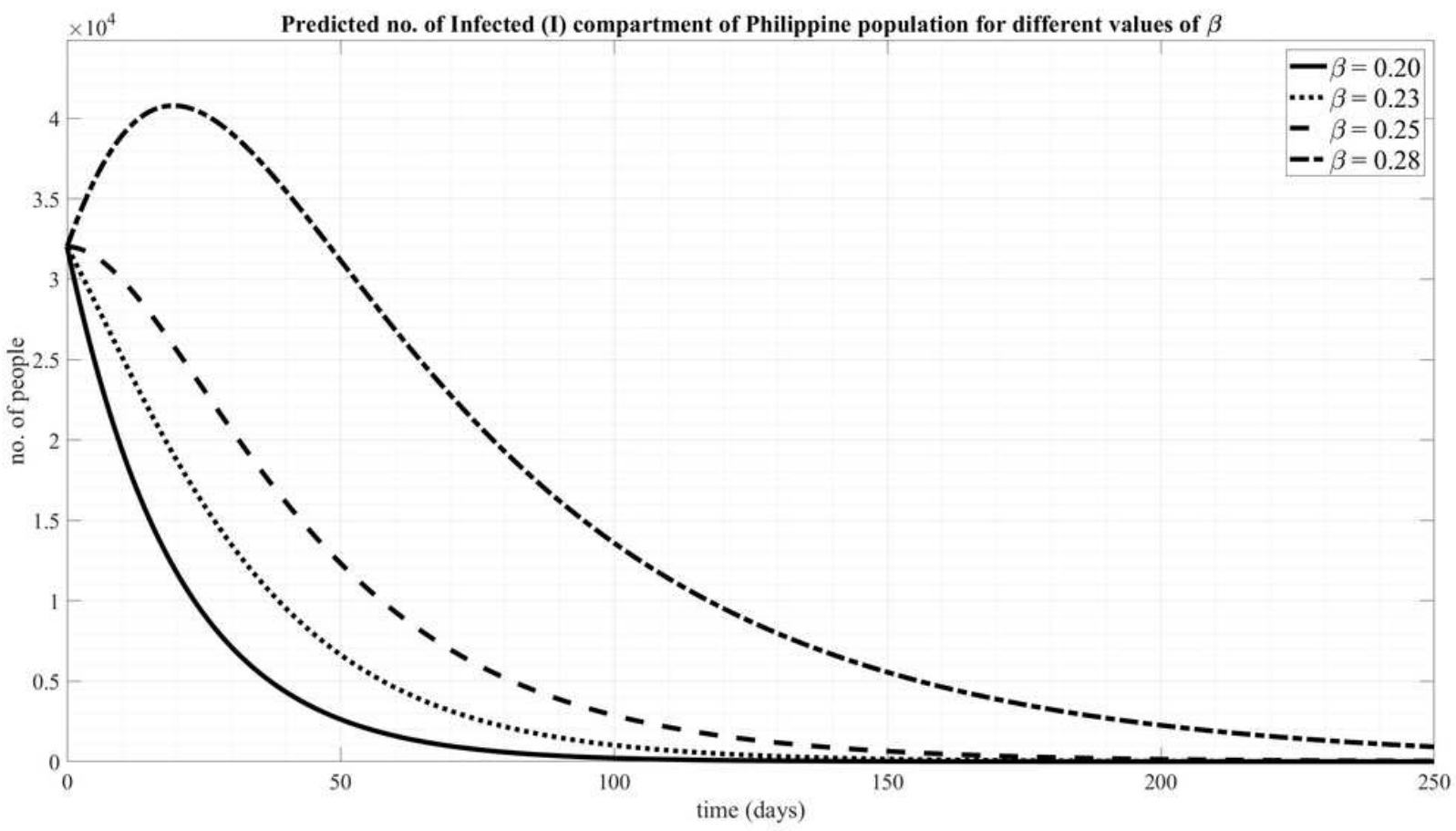

Figure 5

Predicted number of Infected (I) compartment of Philippine population for different values of $\beta$ 


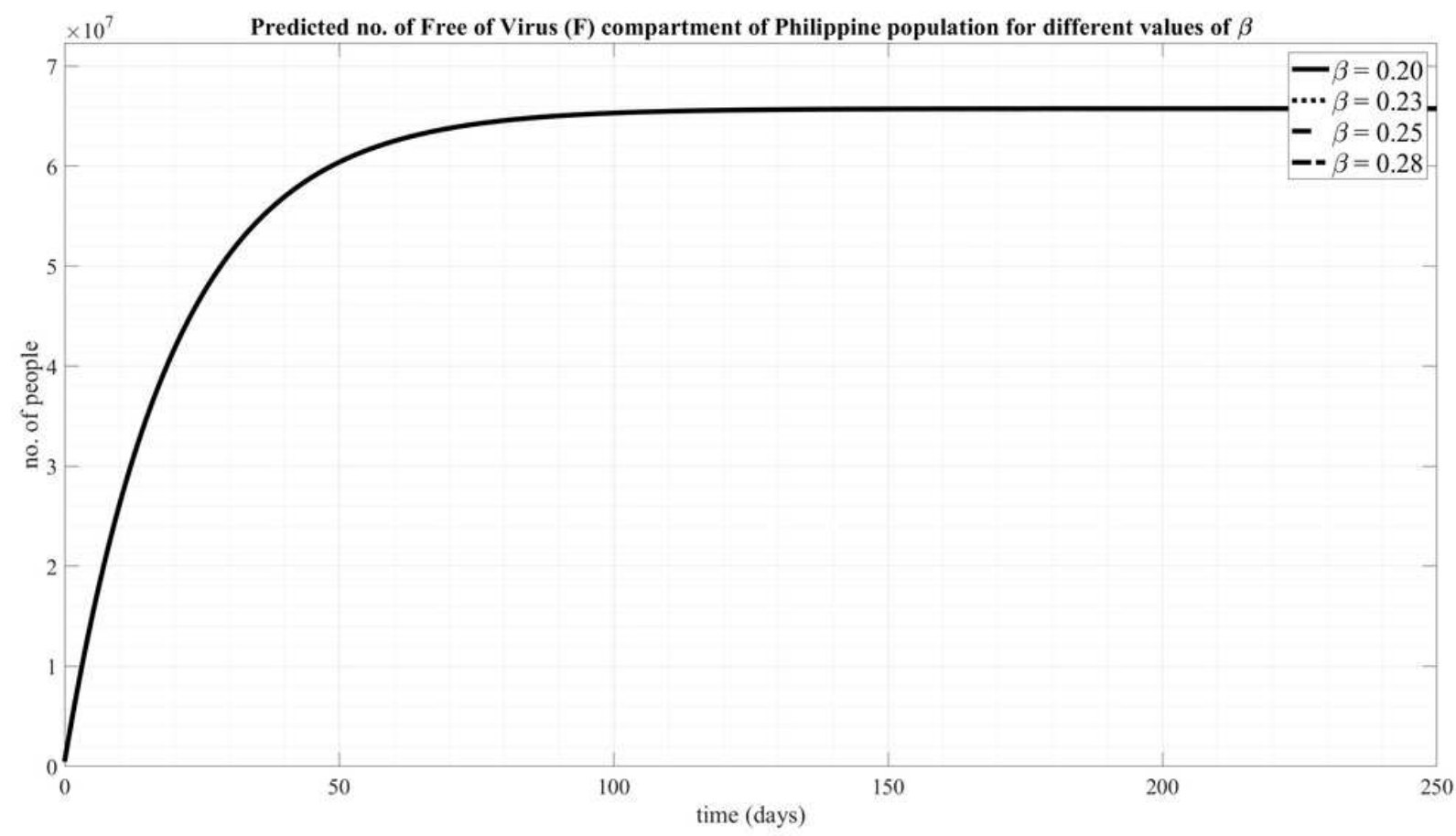

\section{Figure 6}

Predicted number of Free of Virus (F) compartment of Philippine population for different values of $\beta$

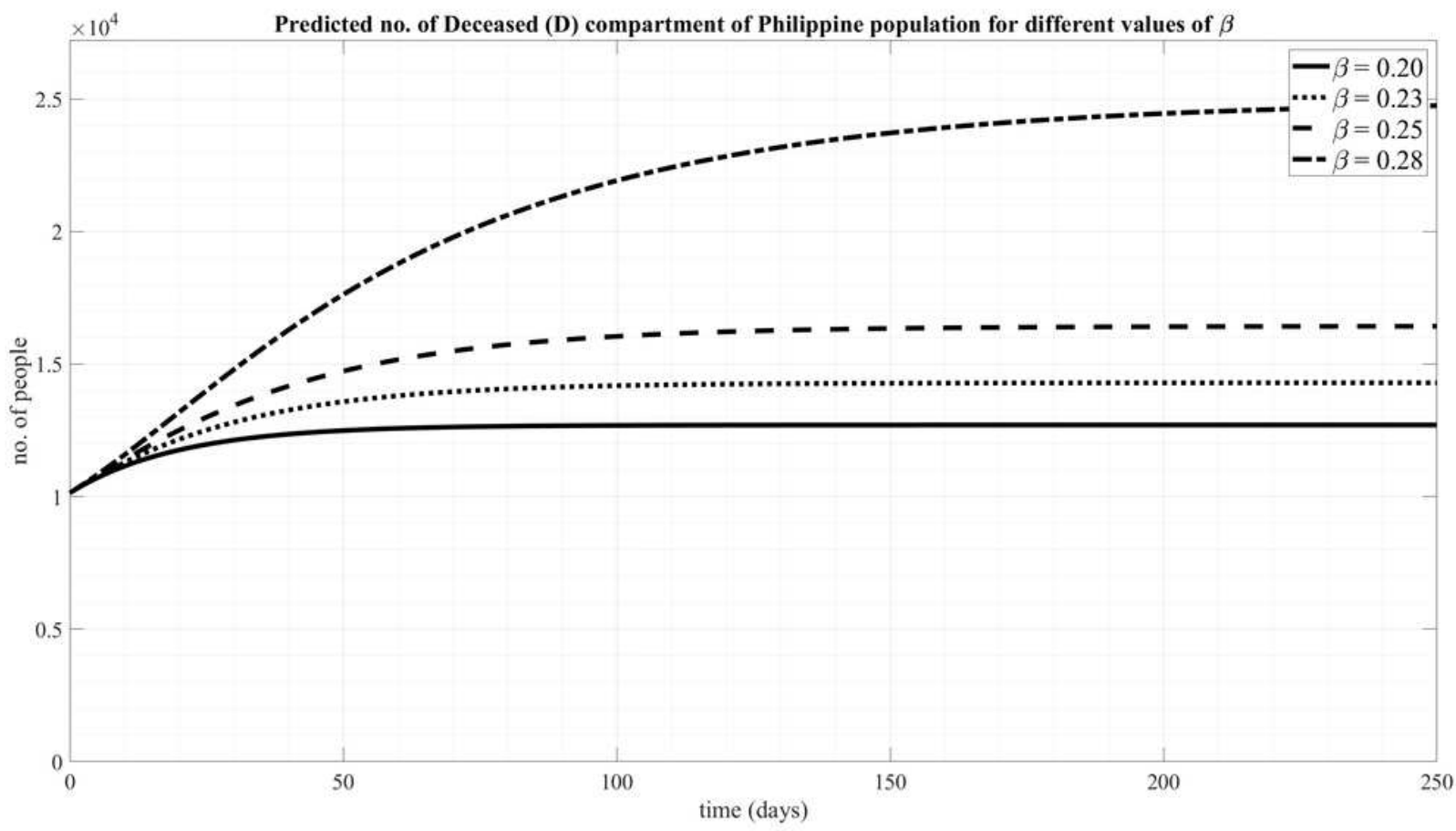

\section{Figure 7}

Predicted number of Deceased (D) compartment of Philippine population for different values of $\beta$ 


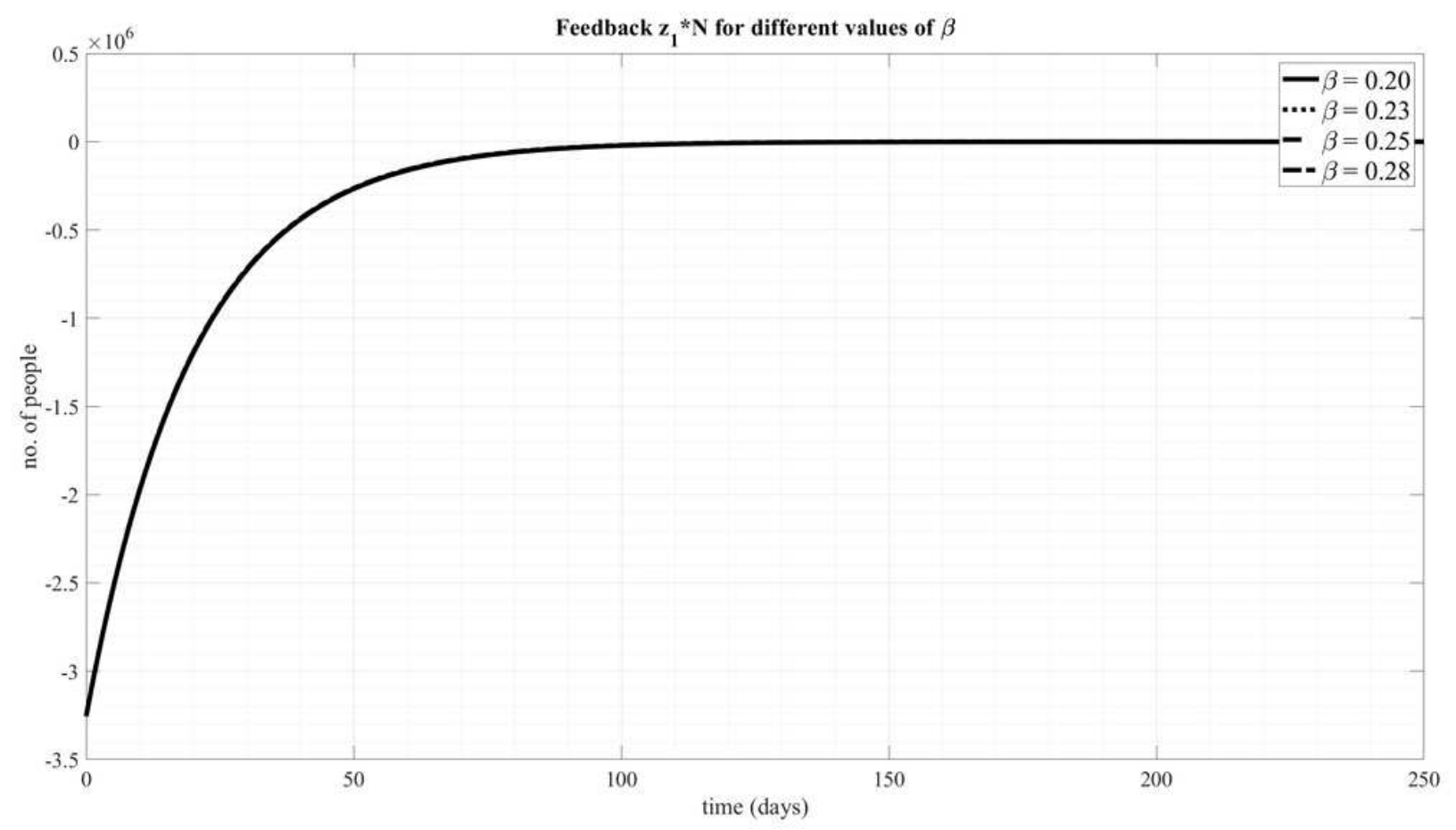

Figure 8

Feedback $z 1^{*} \mathrm{~N}$ for different values of $\beta$

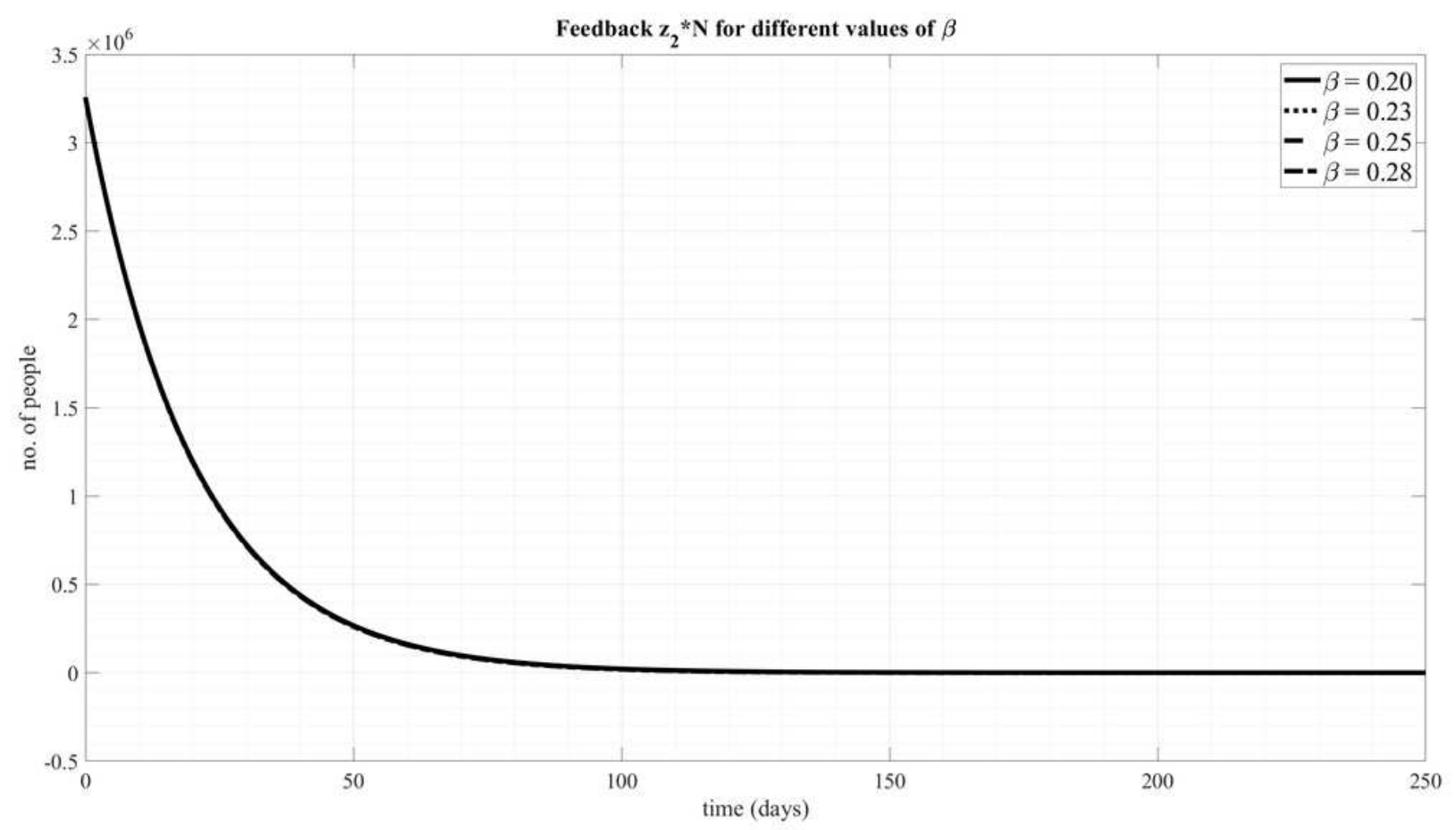

Figure 9

Feedback $z 2^{\star} N$ for different values of $\beta$ 


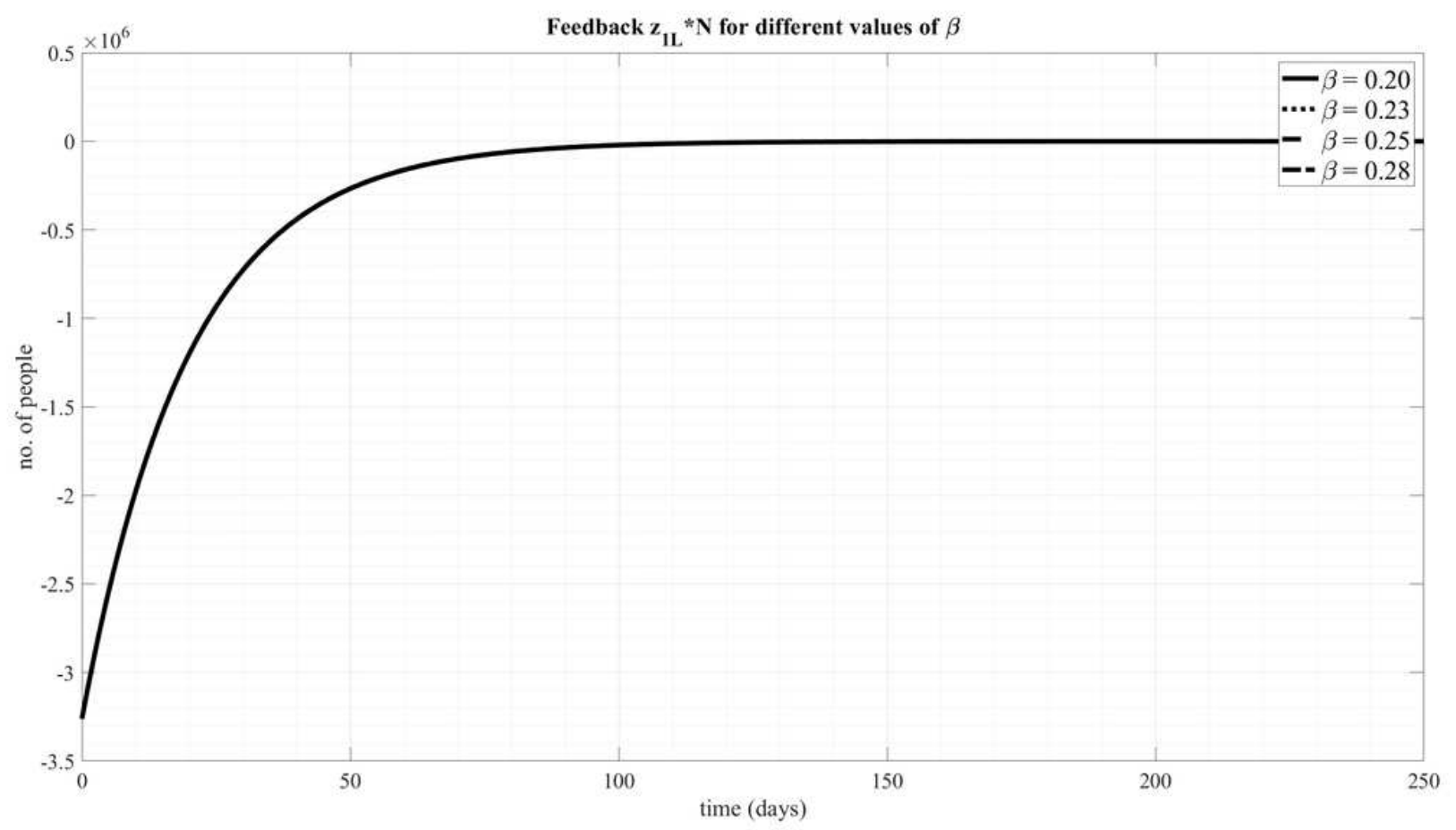

Figure 10

Feedback $z 1 L * N$ for different values of $\beta$

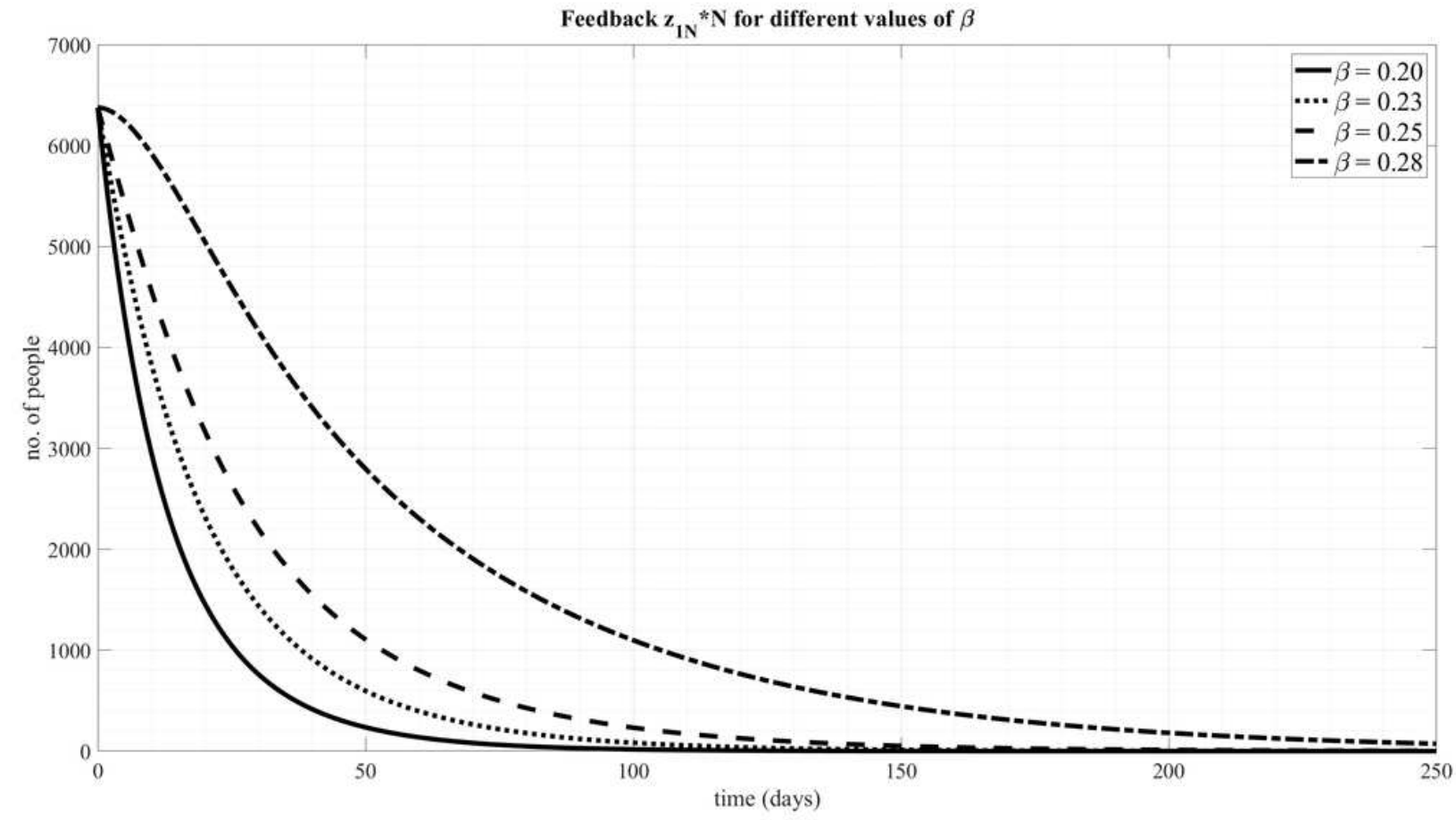

Figure 11

Feedback $z 1 N^{\star} N$ for different values of $\beta$ 


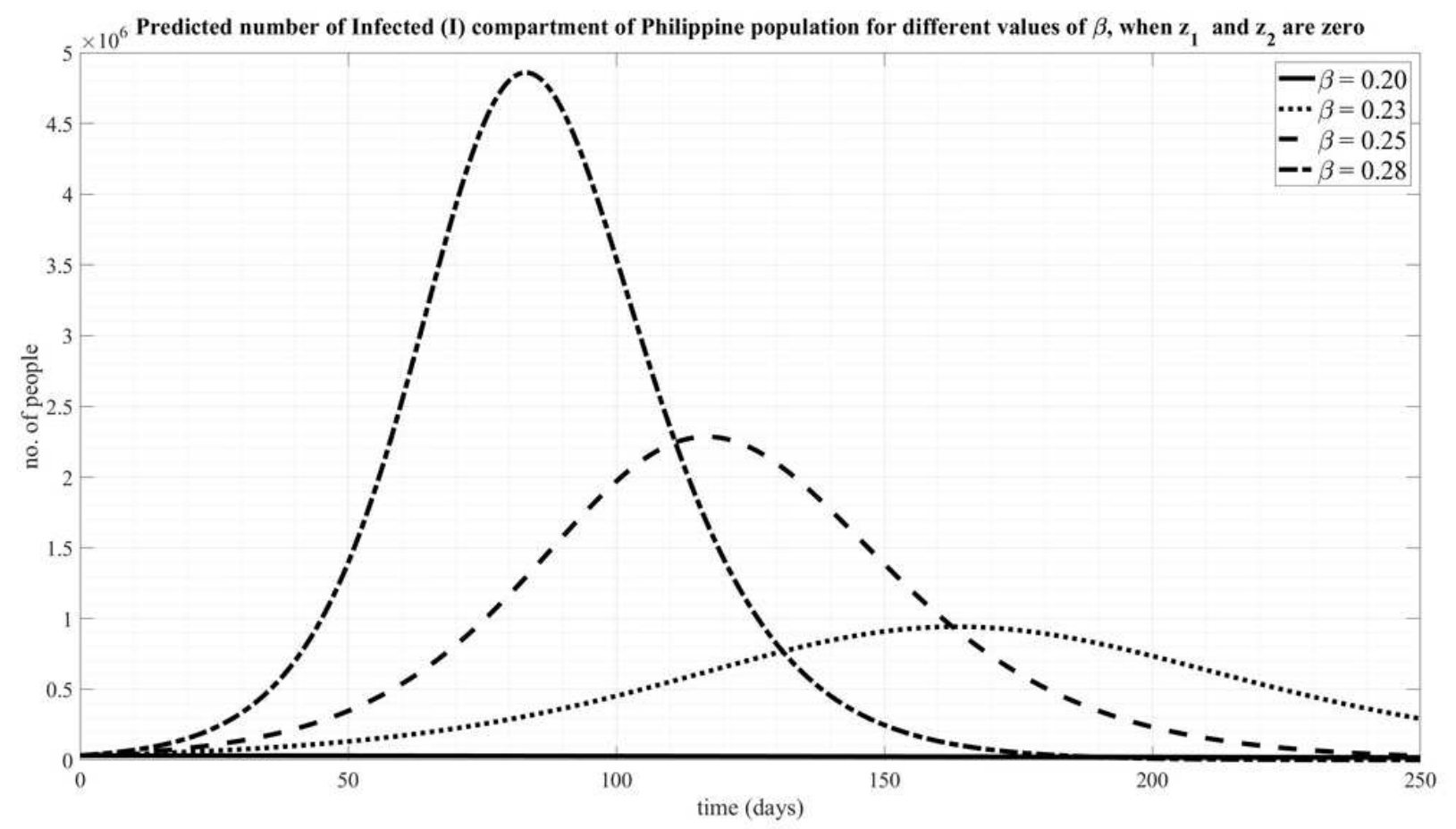

Figure 12

Predicted number of Infected (I) compartment of Philippine population for different values of $\beta$ when z1 and $z 2$ are 0

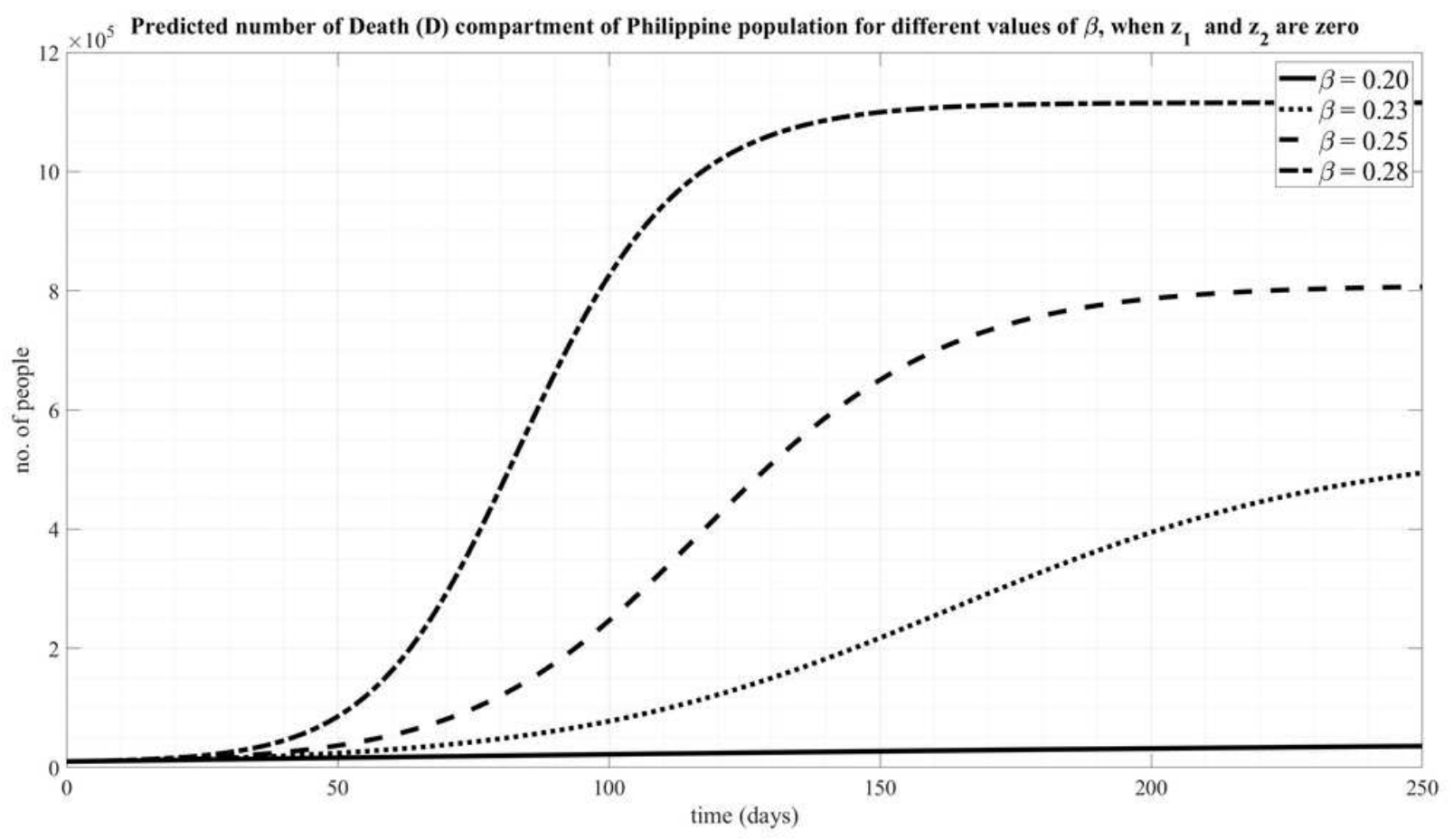

Figure 13 
Predicted number of Death (D) compartment of Philippine population for different values of $\beta$ when $z 1$ and $z 2$ are zero 